\title{
The effects of infantile experience on later emotionality and sensory discrimination '
}

\author{
JAMES G. MAY \\ LOUISIANA STATE UNIVERSITY IN NEW ORLEANS
}

Thirty-nine albino rats from four litters were assigned to one of four groups according to a table of random numbers. The treatments consisted of handling, shock, and two appropriate control situations and were administered from 7-21 days of age. Measures of mobility, defecation, and sensitivity to electric shock, taken at ages 71-74 days, revealed that handled Ss were more sensitive to differences in electric shock intensity than their non-handled controls, while shocked Ss were significantly more emotional than all other groups.

Many investigators have concluded that early experience with stress affects later emotionality (Weininger, 1956; Levine, 1959; Denenberg \& Smith, 1963), learning (Levine, Chevalier, \& Korchin, 1956), and stress tolerance (Denenberg \& Karas, 1960). Griffiths (1960) has indicated that differential sensory input may be a critical factor in the determination of later behavioral adjustment. Both isolation and electric shock (viewed as extremes in sensory input) were reported to result in increased escape thresholds (from electric shock) as compared to controls. Lindholm (1960) has also implied that sensitivity and sensory discrimination should be considered in an explanation of the effects of electric shock. He has recognized two possible hypotheses which are current in research on early painful experience. They are (1) that early trauma increases susceptibility to later emotional disturbances in the form of conditioned fear responses, and (2) that early experience with painful stimuli may result in a decreased reactivity to later emotional disturbances through the mechanism of adaptation. While Griffiths and Lindholm suggest generally that sensory discrimination mechanisms are affected by early experience, a serious consideration of this point has not been undertaken. Thus, the initial concern of this paper centered around a demonstration of differential sensory discrimination as a function of infantile experience.

It is, in general, true that research in the area of infantile stimulation is extensive, but many controversies and conflicts in interpretation abide. A second objective of this study was concerned with a reexamination of the possible relationship between electric shock in infancy and later emotionality. It has been reported by some investigators (Griffiths \& Stringer, 1952; Scott, 1955; Brookshire et al, 1961) that differences in infantile stimulation conditions do not lead to correlated differences in emotionality, while others (Weininger, 1956; Denenberg \& Smith 1963) offer results which indicate that differential emotionality may be a function of differences in early experience.

\section{Method}

The Ss were four litters of albino rats of the Holtzman strain $(N=39)$. Each $S$ was randomly assigned to one of four experimental treatments, systematically marked and caged with its litter until weaned at 18 days of age. After weaning the animals were housed, two per cage, with treatment mates of the same sex and maintained on a standard laboratory diet and ad lib water.

At 7 days of age, each $S$ received one of the following treatments: (a) handling $(N=12)$-each $S$ was transported to a small wooden box ( $6 \times 6 \times 6$ in., floored with plywood) and allowed to remain there for $3 \mathrm{~min}$; (b) shock $(\mathrm{N}=10)$-animals in this group were placed in a small wooden box ( $6 \times 6 \times 6$ in.) which was equipped with a grid floor, and shocked for $3 \mathrm{~min}$ through a 78000 ohm resistor from a $110 \mathrm{~V}$ ac source; (c) handling control $(\mathrm{N}=8)-\mathrm{Ss}$ in this condition were held only long enough to mark with indelible ink and were otherwise left undisturbed; (d) shock control $(\mathrm{N}=9)$-this treatment replicated the procedure of the shock group with the exception that Ss were not shocked. All treatments were administered once per day from the 7 th to the 21st day of life.

At 71 days of age, each $S$ was placed in the testing apparatus which consisted of a Plexiglas chamber (height, 3 in.; length, $2 \mathrm{ft}$; width, $1 \mathrm{ft}$ ) with a double grid floor. Measures of mobility and defecation were recorded during the first minute of the test period using the technique described by Elder (1964). Exactly 1 min after $S$ had been placed in the test chamber, both grids became electrified at $0.10 \mathrm{~mA}$. (The shock circult was a modified version of that described by Wycoff \& Page, 1954.) The left grid was maintained continuously at this shock intensity throughout the test. Across the right grid, however, an intermittent shock was applied once every $5 \mathrm{sec}$ at a train duration of $0.5 \mathrm{sec}$. The first six shocks presented to $S$ on this grid were $0.10 \mathrm{~mA}$ in intensity. The next six shocks received by $S$ were 0.15 $\mathrm{mA}$ in intensity. Thus, the level of shock intensity on the intermittent grid was systematically increased by $0.05 \mathrm{~mA}$ after every six shocks received by $\mathrm{S}$ on that grid. The continuous grid was always available, allowing $S$ to choose whichever grid presented him with the least stressful situation. When $S$ had remained on the continuous grid for $60 \mathrm{sec}$ continuously, a preference was considered to be established, the test was termlnated, and the current level of the last intermittent shock received by $S$ was recorded. This entire procedure was carried out for each $S$ once per day for four consecutive days. 


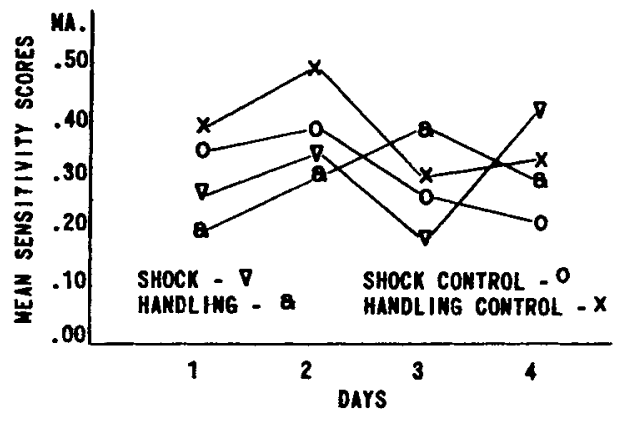

Fig. 1. Mean sensitivity scores for all groups on all four test days.

\section{Results and Discussion}

Initially, three sets of data (defecation, mobility, and sensitivity scores) were analyzed in three Linquist Type I designs. It was found, however, that significant effects of infantile stimulation on the first day's scores were being obscured by the repeated measures utilized in such a design. Consequently, only the first day's data were considered in three simple analysis of variance designs. This change in analytical technique revealed that infantile treatments were significant in terms of sensitivity ( $F=4.37, d f=3 / 35, p<.05$ ) and mobility ( $F$ $=3.51, d f=3 / 35, p<.05$ ), but not in terms of defecation. It also implied that repeated testing in the situation results in contamination of the first day's scores (which measure variation deriving from the infantile treatments) with variation due to conditioned fear responses acquired during testing.

A plot of the mean sensitivity scores for each group on Day $1,2,3$, and 4 of testing indicate that the handled group differed significantly $(t=2.26, d f=16, p<.05)$ from the handling control animals in the ability to detect increments in intermittent shock intensity on Day 1. While in the same direction, the difference between the shock and shock control groups did not achieve significance. A curvilinear correlation ratio $(E t a=.47)$ was obtained between infantile treatments and sensitivity scores, indicating that slightly over $20 \%$ of the univariate error was accounted for through knowledge of early stimulation conditions. These results are taken to indicate that sensitivity has been implemented as a factor mediating the effects of experience with electric shock and handling.

The data concerned with emotionality as a function

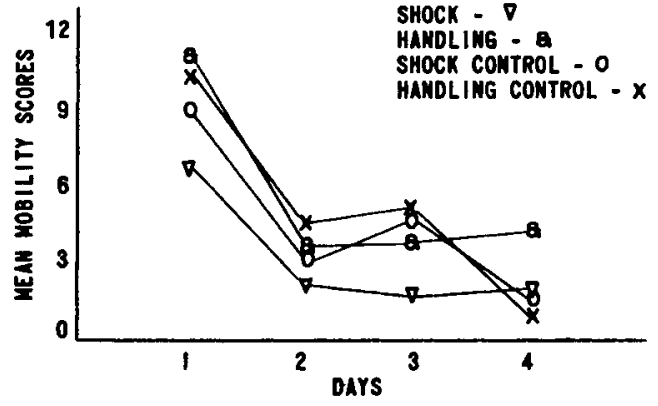

Fig. 2. Mean mobility scores for all groups on all four test days.

of infantile treatments are presented in Fig. 2 (a comparison of mean mobility scores for all groups on Days $1,2,3$, and 4 of testing). It can be seen that the shocked group exhibited more emotionality than any other group on Day $1(t=3.78$, df $=20, p<.01)$. Significant differences in mobility scores were not found between any of the other three groups. A strong relationship was found $(\mathrm{Eta}=.47)$ between infantile treatments and emothonality. This outcome supports the view that early experience with shock results in increased emotionality later in life (Weininger, 1956; Denenberg \& Smith, 1963).

\section{References ${ }^{2}$}

BROOKSHIRE, K. H., LITTMAN, R. A., \& STEWART, C. W. Residua of shock-trauma in the white rat: a three factor theory. Psychol. Monogr., 1961, 75, 32.

DENENBERG, V. H., \& SMITH, S. A. Effects of infantile stimulation and age upon behavior. J. comp. physiol Psychol, 1963, 56, 307312.

ELDER, S. T. The influences of anterior cortical lesions upon the CER to an auditory stimulus under conditions of nonextinction. Psychol. Rep., 1964, 14, 603-610.

GRIFFITHS, W. J., Jr., Effects of isolation and stress on escape thresholds in albino rats. Psychol. Rep., 1960, 6, 23-29.

LEVINE, $S$. The effects of differential infantile stimulation on emotionality at weaning. Canad. J. Psychol, 1959, 13, 243-247.

LINDHOLM, B. W. Critical periods and the effects of early shock on later emotional behavior in the white rat. J. comp. physiol. Psychol, $1962,55,597-599$.

WYKOFF, L. B., \&PAGE, H. A. A grid for administering shock. Amer. J. Psychol, 1954, 64, 154.

\section{Notes}

1. Submitted in partial fulfillment of M.S. degree from the University of Southern Mississippi, 1966. The author is indebted to Dr. Harry R. Barker for advice and encouragement.

2. Unlisted references may be found in Brookshire et al. 